\title{
Structural characterization and transcriptional pattern of two types of carp rhodopsin gene
}

\author{
Chih-Ying Su, Jormay Lim, Huai-Jen Tsai* \\ Institute of Fisheries Science, National Taiwan University, Section 4, 1 Roosevelt Road, Taipei 106, Taiwan, ROC
}

Received 19 May 1999; received in revised form 30 August 1999; accepted 1 September 1999

\begin{abstract}
This work characterizes the genomic structures of two types of carp (Cyprinus carpio) rhodopsin $(c R h)$ gene, i.e. type I $(c R h-I)$ and type II $(c R h-I I)$. Two types of $c R h$ gene share only $45.6 \%$ polynucleotide identity in the upstream region from nucleotide -3436 to +97 . However, three conserved regions are found. Homologies to the consensus recognition sites for transcription factors, $\mathrm{Crx}$ and $\mathrm{Nrl}$, which are involved in photoreceptor-specific expression, are also observed in $c R h$ genes. With specific polymerase chain reaction (PCR) primers, the two types of $c R h$ gene can be clearly discriminated from each carp genome. Most carps exhibit both types of $c R h$ gene, however, there are still carps possessing either $c R h-I$ or $c R h-I I$. Both $c R h-I$ and $c R h-I I$ mRNAs are expressed at an approximately equal level in both eyes extracted from a carp carrying both types of $c R h$ gene. () 2000 Elsevier Science Inc. All rights reserved.
\end{abstract}

Keywords: Cyprinus carpio; Fish; Genomic structure; PCR; Photoreceptor; Rhodopsin; Sequence comparison; Type discrimination

\section{Introduction}

Eyes are photoreceptor organs that contribute to image formation. Photoreceptor cells consist of rods and cones. Rods are sensitive to dim light, while cones contribute to daytime vision and color perception. Each photoreceptor consists of a seven-transmembrane protein, opsin, to which its chromophore, 11-cis-retinal, is attached (Rose et al., 1989). Previous investigations have reported on the presence of rhodopsin cDNA in extremely broad varieties, such as bovine (Nathans and Hogness, 1983), humans (Nathans and Hogness, 1984), chickens (Takao et al., 1988), mice (Baehr et al., 1988), rats (Morabito et al., 1991), lizards (Kawamura and Yokayama, 1994), canines (Pe-

\footnotetext{
* Corresponding author. Tel.: + 886-2-2366-1540; fax: + 886-2-2363-8483.

E-mail address: hjtsai@ccms.ntu.edu.tw (H.-J. Tsai)
}

terson-Jones et al., 1994), old world monkeys (Nickells et al., 1995), salamanders (Chen et al., 1996), Xenopus (Saha and Grainger, 1993; Batni et al., 1996), squids (Hall et al., 1991; HaraNishimura et al., 1993), lamprey (Hisatomi et al., 1991), goldfish (Johnson et al., 1992), marine lamprey (Zhang and Yokoyama, 1997), skates (O’Brien et al., 1997), carps (Tsai et al., 1994; Lim et al., 1997) and marine fish, John Dory (Archer and Hirano, 1998). These studies include terrestrial animals, amphibians and aquatic animals. Nevertheless, genomic structure of rhodopsin was studied primarily in Xenopus (Batni et al., 1996), chickens (Takao et al., 1988) and mammals, such as bovine (Nathans and Hogness, 1983), humans (Nathans and Hogness 1984; Bennett et al., 1995), mice (Baehr et al., 1988), and rats (Morabito et al., 1991). Those investigations demonstrate that rhodopsin gene contains four or five introns. Interestingly, Fitzgibbon et al. (1995) indicated that 
the rhodopsin gene of bony fish is intron-free, although the genomic structures of those bony fish have not been completely characterized. Among all the species studied, only one type of rhodopsin gene has been reported except Xenopus and the one studied in a previous investigation, the common carps (Lim et al., 1997).

In light of above discussion, this study demonstrates the rhodopsin genomic structures of the most primitive vertebrate, fish. The entire molecular sequences corresponding to two types of carp rhodopsin $(c R h)$ cDNAs are elucidated. In addition, type discriminations and transcription patterns of $c R h$ genes are studied as well. Comparing the polynucleotide sequences of the upstream region and investigating the transcriptional patterns of type I $c R h(c R h-I)$ and type II $c R h(c R h-I I)$ genes facilitate an understanding of the rhodopsin gene regulation of fish. More thoroughly understanding rhodopsin genes of diverse species will provide further insight into visual systems.

\section{Materials and methods}

\subsection{Genomic library construction, screening and subcloning}

Genomic DNA extracted from carp blood (Sambrook et al., 1989) was utilized to construct the genomic DNA library by using Lamda FIX ${ }^{\circledR}$ II/XhoI Partial Fill-In Vector Kit and Gigapack ${ }^{\circledR}$ III Gold Packaging Extract (Stratagene). Approximately 60000 phages were hybridized by a radiolabeled probe $(1.3 \mathrm{~kb}$ fragment of $c R h-I$ cDNA) overnight at $42^{\circ} \mathrm{C}$. The membranes were washed and then exposed to X-ray films. Each putative phage clone $(100 \mu \mathrm{l})$ was heated and vigorously vortexed as a template for polymerase chain reaction (PCR). Type-specific primers were used to detect the $c R h-I$ and $c R h-I I$ genes. PCR was performed for 25 cycles in a $20 \mu$ l solution containing $7 \mu \mathrm{l}$ of phage lysate, $0.2 \mathrm{mM}$ of dNTP, 0.5 $\mu \mathrm{M}$ of primers, $1 \times$ buffer and $2.5 \mathrm{U}$ VioTaq DNA polymerase (Viogene). Each amplification cycle consisted of denaturation at $94^{\circ} \mathrm{C}$ for $1 \mathrm{~min}$, annealing at $62^{\circ} \mathrm{C}$ for $1 \mathrm{~min}$, and extension at $72^{\circ} \mathrm{C}$ for $1 \mathrm{~min}$.

Insert fragments were excised from recombinant phage DNA by SalI digestion and purified by gel extraction. The $5^{\prime}$ and $3^{\prime}$ flanking regions of $c R h$ genes were determined by PCR using the upstream- and downstream-specific primers (5'GGCTGCGGTTGGATGTTGT-3'， 5'-CTGATAAGTGCCAGATATG C-3'， 5'-CCCCGGGAAAGAGCAACCA-3' and 5'-CATGCCTCTACAATCACAACAAA-3'). Insert fragments were then subcloned into pBluescript ${ }^{\circledR}$ II SK $(+/-)$ vector.

\subsection{The primer extension assay}

Total retinal RNA from adult carps dissected during the daytime was extracted with TRI Reagent (Molecular Research Center, Inc). The $\left[\gamma-{ }^{33}\right.$ p]ATP-labeled primers were hybridized by retinal RNA at $50^{\circ} \mathrm{C}$ for $22 \mathrm{~h}$, and then precipitated by ethanol. The pellet was resuspended in reverse transcription buffer and reversely transcribed with SuperScript ${ }^{\mathrm{TM}}$ II $\mathrm{RNaseH}^{-}$Reverse Transcriptase (Gibco BRL). Finally, the extension reaction was loaded along with the sequencing reaction of the subcloned DNA sequenced with the same primer on a $6 \%$ polyacrylamide $/ 8 \mathrm{M}$ urea gel.

\subsection{Sequence analysis}

Sequencing was performed with Dye Terminator Cycle Sequencing Ready Reaction Kit (ABI) and analyzed on ABI PRISM ${ }^{\mathrm{TM}} 310$ Genetic Analyzer. Polynucleotide sequences were read at both ends and analyzed with PC/GENE ${ }^{\circledR}$ Program (IntelliGenetics).

\subsection{Type discrimination}

Fifty nanograms of genomic DNA extracted from carp blood (Sambrook et al., 1989) was used as template to perform PCR reaction with typespecific primers as above description. The PCR products were digested by $T f i$ I for differentiating $c R h-I$ and $c R h-I I$ genes. In total, 100 carps randomly selected from the local aquacultural ponds (Tzu-Pei, located in northern Taiwan and LuKang, located in middle Taiwan) were analyzed for the distribution frequency of $c R h-I$ and $c R h-I I$ genotypes.

\subsection{Transcription pattern}

Total retinal RNA of each eye of an adult carp carrying both $c R h-I$ and $c R h-I I$ genes was extracted and reversely transcribed as above descrip- 


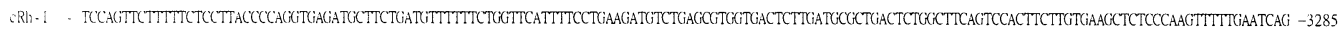
$\begin{array}{lllllllllllllllllllllllllll}11 & 1 & 1 & 1 & 1 & 11 & 1 & 11 & 11 & 11 & 11 & 1 & 1 & 1 & 1 & 1 & 1 & 1 & 1 & 11 & 11 & 1 & 1 & 1\end{array}$

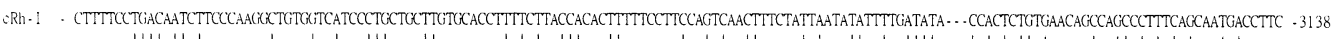

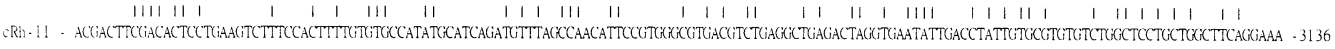

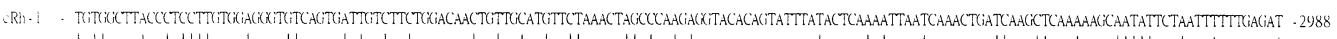

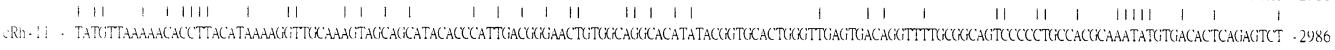

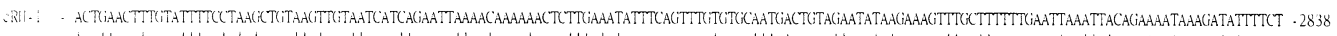

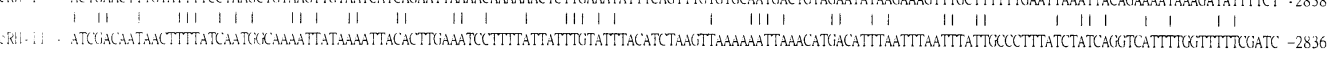

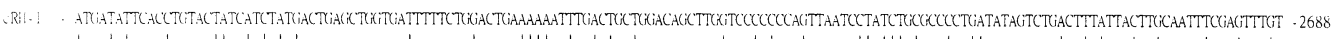

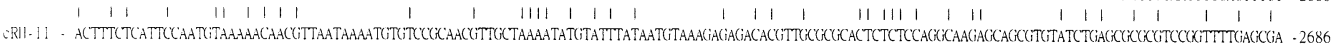

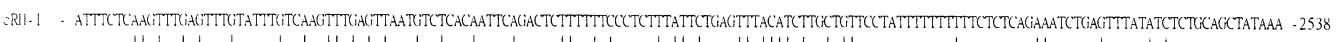

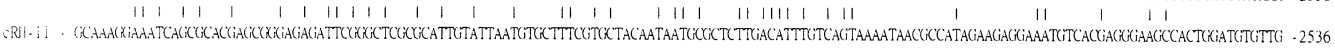

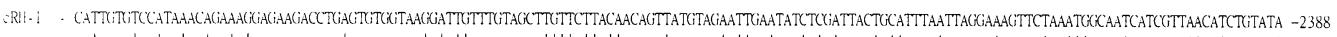

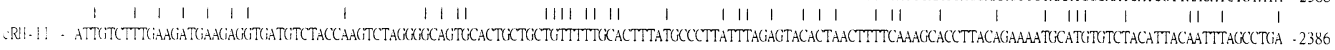

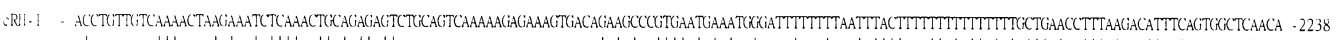

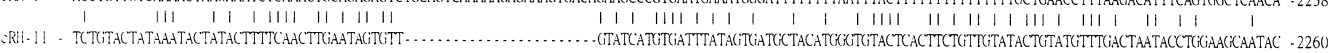

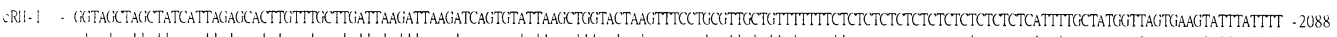

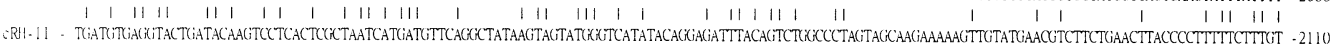

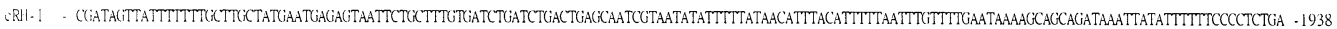

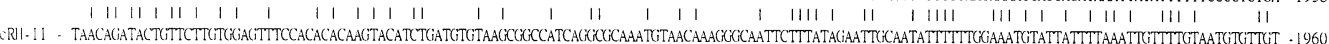

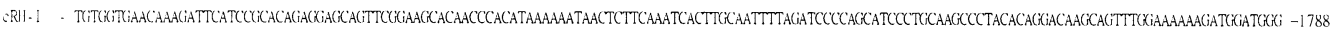

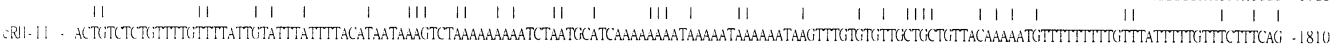

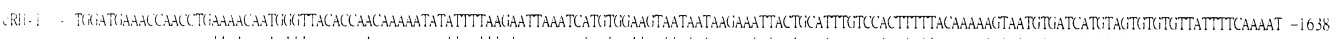

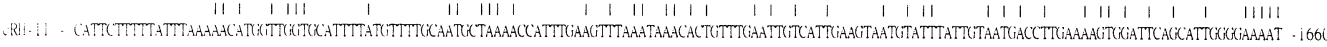

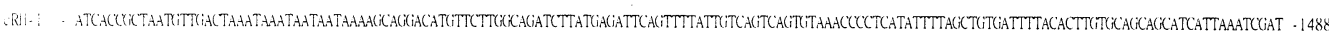

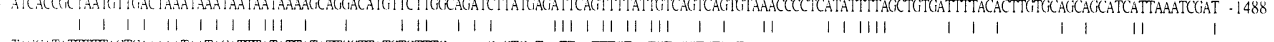

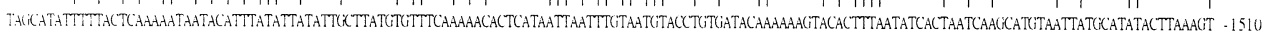

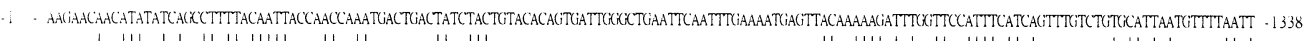

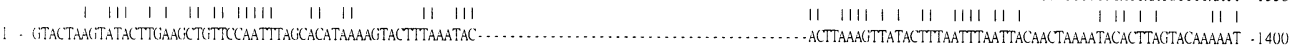

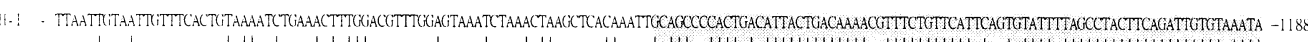

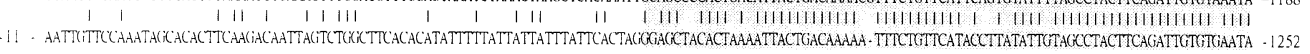

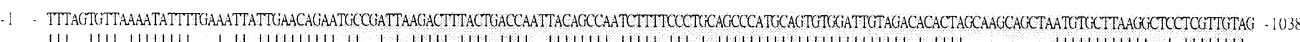

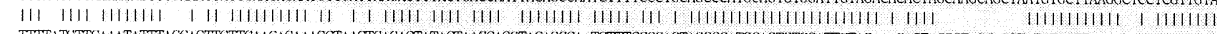

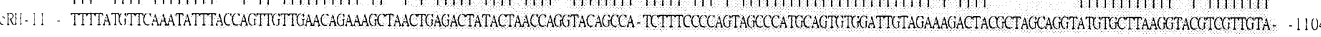

-RI-1 - AGTAACTCTCCTGTAATCTGTAAATCCTCTTCATAAAACCCACCTGTAAGAAATATGCTGAGCCTTGAGCATTTCAACCCAGGCATTTCATAGTGCCAAGGGTACCCTTAGTCCACCTGACACTACACAATCTAGGATATAGAGGAGAGG -888

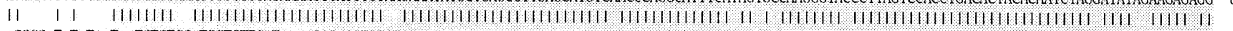

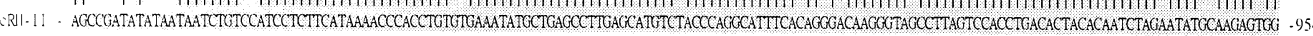

:RI-1 - AAATAAATTAATACCAAGTATTCTTGTGTTAATCCACTGGTTTAATATCCTGAATTAAAATGACTGATGAATGAATTTTGTATTATTGAATTAATGTGCTTGATTAAATTGGATGATTACTAAGAACAGTAGTTAAAGAGACGTGCA -738

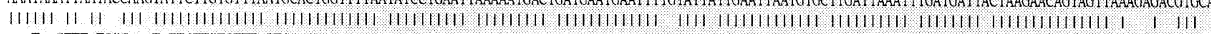

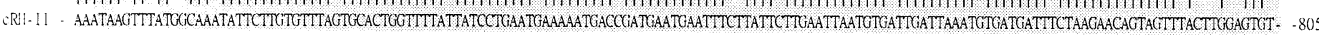

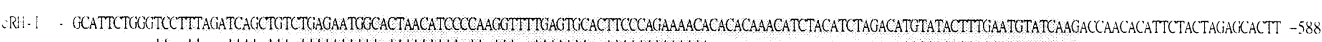

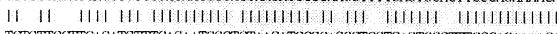

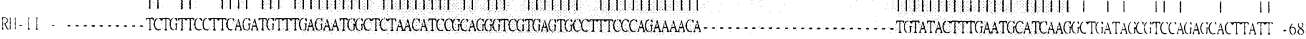

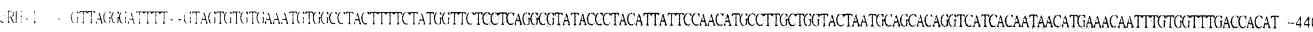

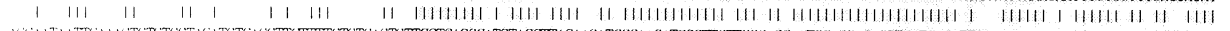

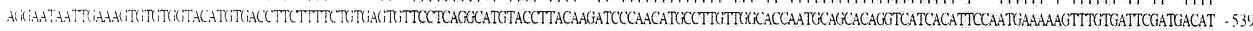

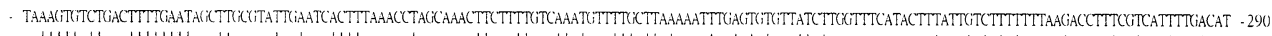

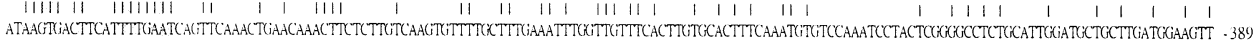

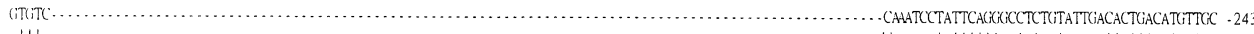

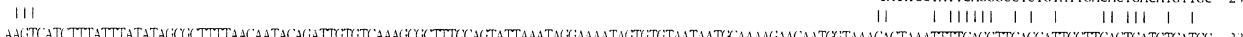
CAAT Box

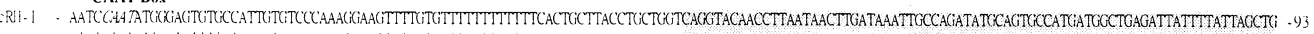

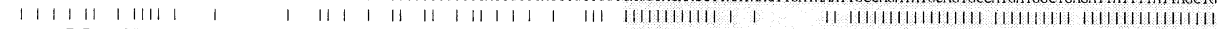

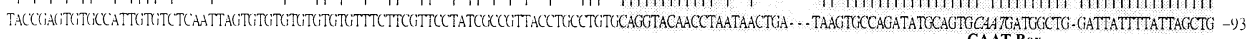

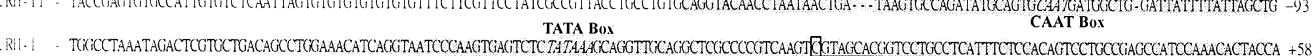

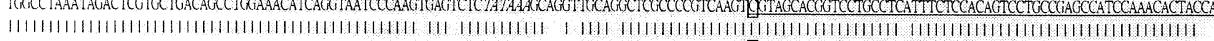

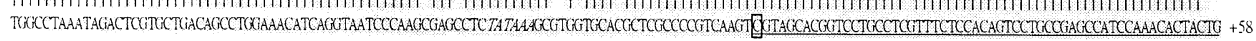

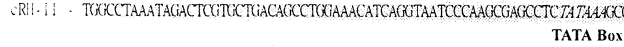

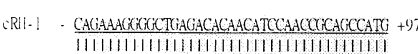

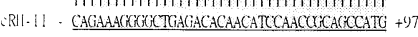

Fig. 1. Comparison of the upstream (A) and downstream (B) polynucleotides of the type I ( $c R h-I)$ and type II (cRh-II) rhodopsin genes of carp. Numbers on the right side of each column represent the nucleotide position relative to transcription start site $(+1)$, which is boxed. The transcribed region is underlined. TATA and CAAT boxes of $c R h-I$ and $c R h-I I$ genes are indicated above and below, respectively. Identical bases are denoted by vertical bars. Gaps, denoted by broken lines, are introduced to maximize identities. Regions containing greater than $75 \%$ identity between the upstream region of two types of $c R h$ genes are shaded. The polyadenylation signals found in cDNA clones are in boldface and italics. 
tion. The RNA was removed by $\mathrm{RNaseH}$ digestion. PCR was performed with type-specific primers as described above except that retinal cDNA was used as a template.

\section{Results and discussion}

\subsection{Isolation of recombinant phages containing $c$ Rh genes}

A genomic DNA library of titer $10^{11} \mathrm{pfu} / \mathrm{ml}$ was constructed. Two $c R h-I$ clones and three $c R h-I I$ clones were isolated from the library. Thereafter, recombinant phages contained $14 \mathrm{~kb}$ of $c R h-I$ insert and $10 \mathrm{~kb}$ of $c R h-I I$ insert were obtained, respectively. After restriction mapping and subcloning, DNA fragments around 3.4 and $0.3 \mathrm{~kb}$ containing upstream and downstream flanking regions of $c R h$ genes, respectively, were sequenced (Fig. 1). These sequences are submitted to the EMBL/GeneBank/DDBJ databases under Accession No. AJ 012013, AJ 012009, AJ 012014 and AJ 012010.

\subsection{Characterization of both types of $c R h$ gene}

The primer extension assay revealed that the transcription initiation site $(+1)$ of $c R h$ was 94 bp upstream of the start codon (data not shown). A TATA box was observed at nucleotide (nt) $-33 \sim-36$ in both $c R h-I$ and $c R h$ II genes. As generally known, this nt position is relatively conserved among all known species. Similar to the rhodopsin gene of mice (Baehr et al., 1988), the $c R h-I I$ gene had a CAAT box at nt -121 to -118 . However, the $c R h-I$ gene had a CAAT box at nt -235 to -238 , which was $120 \mathrm{bp}$ ahead of that of $c R h-I I$ gene (Fig. 1A). Both types of $c R h$ gene were intronless. This finding correlates with Fitzgibbon et al. (1995), which contended that rhodopsin gene of bony fish lacks intron.

\subsection{Upstream flanking sequences analysis}

Compared to the $c R h-I I$ gene, the $c R h-I$ gene shared only $45.6 \%$ polynucleotide identity in the upstream region ranging from $\mathrm{nt}-3434$ to + 97 of $c R h-I$ or from nt -3435 to +97 of $c R h-$ II. However, three relatively highly conserved regions were observed at $\mathrm{nt}-1262$ to -614 , -539 to -419 and -166 to +97 , with 78.0 , 79.3 and $92.3 \%$ identities, respectively (Fig. 1A).

\section{B}

cRH-I TCTTACTGTTGGACTCCTTATACTGGCTTTGTTGTGATTGTAGAGGCATGTATTCAAGGCAACGTAACAATAAAAAGCACTTTGCAAATTAAAT - - TGCT 111111111111111111111111111111111111111111111111111111111111111111111111111111111111111111111111111 1 11 cRH- 1 I TCTTACTGTTGGACTCCTTATACTGGCTTTGTTGTGATTTTAGAGGCATGTATTTAAGGCAACGTAACAATAAAAAGCACTTTGCAAATTAAATCATTCT

cRH-I GTTTATGTTTTAATTGAGCTGTGATGTTAATA-AAATGTCAAAATAGTATTTTAAATTAAATAAAAG-T - - -GATTTCTGATGAGAGTTTTAATGTGGTG

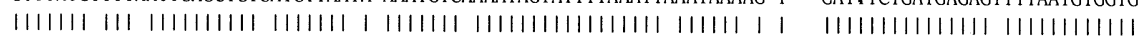
cRH- I I GTTTATGATTTGATTGAGCTGTAATGTTAA-AGAAATGTCTAAATAGTATTTTAAATTTAATAAACGATACTGATTTCTGATGAGAGCTTTAATGTGGTG

CRH - 1 TATATATTCCCACCGCTAATGTCTTCGGTAAAGGCTGAGTGCTTTTTAATCTATTCTTTTTTAATCATCATCAATACGACAGAGTT - -T-CAG-AATT-GA

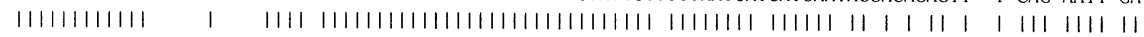
CRH - 11 TATATATTCCCA - ..... - ...-. CTTCAGTAAAGGCTGAGTGCTTTTTAATCTATTCTGTTTAATCAACATCAAGAC - A - ATAGCTACTGCAGGAATTCGA

CRH- 1 AAAAAGTGCATA-CATTACTTCCAAAGTTAACAG-C-ACCATA-ATTATGGATATTA-TAACAGGCTCAATAT-GT - -TATTCAATGCAA- -GTAT - ACG

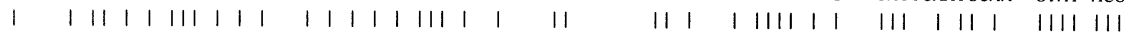
CRH - I I TA - ... - T-CA - AGC-TTA-T-CGA - . - T-ACC-GTCGACC-TCGAGGGGGGGCCCCGGTA - C - . - C-CAAT - TCGCCCTAT - AGTG - AGTCGTATTACG

cRH- I ACCGGGGCAATCCTCACTGTCACCTTGGATTA-AAGGCTTTGTGAAGGATGATTGACAGATATGTATGGATGAA

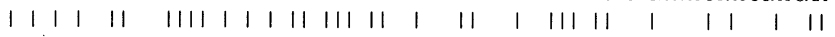

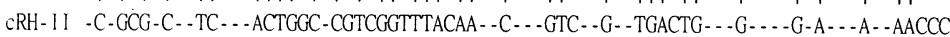




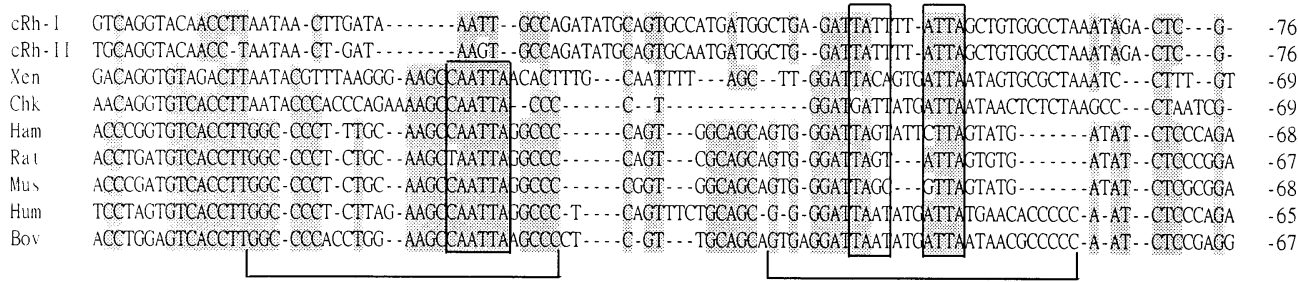

Ret 1

BAT-1

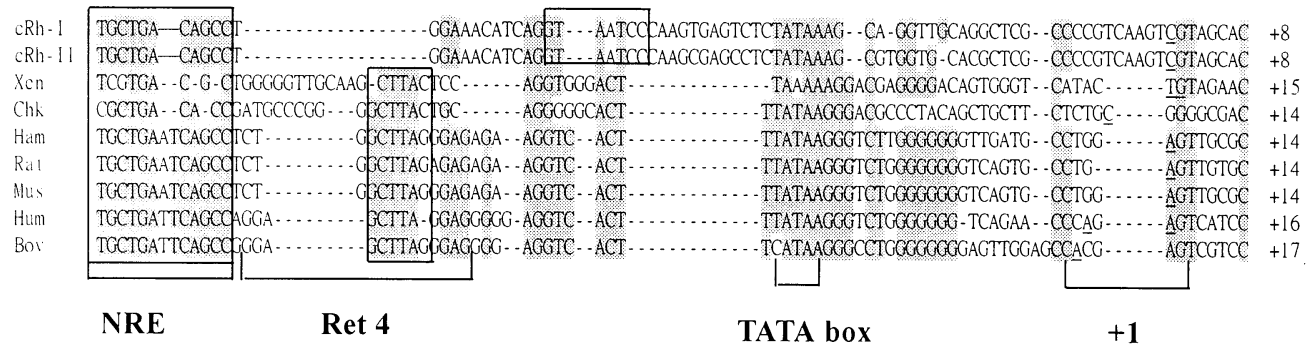

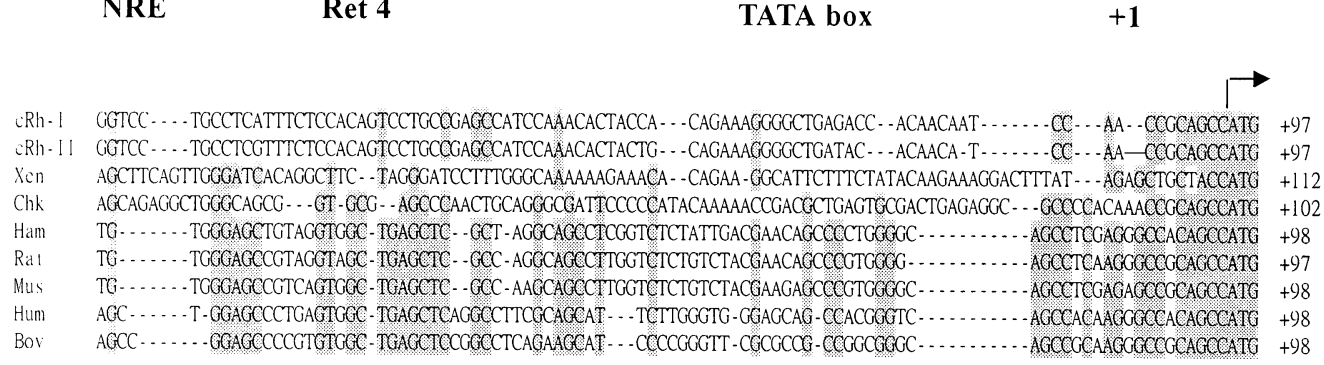

Fig. 2. Nucleotide identities among $c R h$ and other known vertebrates rhodopsin upstream sequences. Sequence alignments of the $\sim 290$ immediate upstream nucleotides of $c R h-I, c R h-I I$, Xenopus (Xen), chickens (Chk), Chinese hamsters (Ham), rats (Rat), mice (Mus), humans (Hum) and bovine (Bov) rhodopsin genes is shown. Numbers on the right side of each column represent the nucleotide position relative to transcription start site $(+1)$, which is underlined. Gaps, indicated by broken lines, are introduced to maximize identities. Shaded areas represent sequences that are identical in all mammalian species; where the sequence of carp, Xenopus or chicken is identical, it is also shaded. Positions of the TATA box, Ret 4, NRE, BAT-1 and Ret 1 of mammals are indicated below the alignment. Boxed regions indicate consensus recognition sites of Crx, which binds to C/TTAATCC, Ret 4, BAT-1 and Ret 1 (Kumar et al., 1996), and Nrl, which binds to NRE (Chen et al., 1997; Rehemtulla et al., 1996). Arrow indicates the translation initiating codon.

In Fig. 2, the proximal upstream flanking sequences of $c R h-I$ and $c R h-I I$ genes are compared with those of known vertebrates (Batni et al., 1996; Chen et al., 1996, 1997). Consensus recognition sites for $\mathrm{Crx}$ and $\mathrm{Nrl}$ are observed in the corresponding regions of $c R h$ genes. $\mathrm{Crx}$ and $\mathrm{Nrl}$ are trans-factors that work synergically to bind to and transactivate the genes for several photoreceptor-specific proteins (Chen et al., 1997). Crx binds independently to three sites in the rhodopsin proximal promoter region of bovine, which are Ret 1 , Ret 4 and BAT-1, and C/ TTAATCC of other photoreceptor-specific genes (Chen et al., 1997); and $\mathrm{Nrl}$ binds to NRE (Kumar et al., 1996; Rehemtulla et al., 1996). In $c R h$ genes, homologies of the binding core regions of BAT-1 and NRE were observed in corresponding sites. In addition, sequence sharing homology to C/TTAATCC was also found at nt $-46 \sim-52$ in $c R h$ genes (Fig. 2). These findings suggest that $\mathrm{Crx}$ and $\mathrm{Nrl}$ may also regulate $c R h$ genes.

Ret 1 core region (CTAATTAG) and its facilitated flanking sequences (GGCCCC) (Morabito et al., 1991; Yu et al., 1996) and Ret 4 (Chen and Zack, 1996) have been proven to play a critical role in driving photoreceptor-specific gene expression in rats. Nevertheless, no corresponding sequence was observed in either $c R h-I$ or $c R h-I I$ gene. In addition, no significant matches were found in $c R h$ genes with the known rhodopsin enhancer region, which is a highly conserved region located at $1.5 \sim 2 \mathrm{~kb}$ upstream of mammalian rhodopsin genes (Nie et al., 1996). 
Except for the consensus recognition sites for $\mathrm{Crx}$ and $\mathrm{Nrl}$, the upstream flanking regions of both types of $c R h$ gene shared relatively low identity with those of other terrestrial vertebrates. This evidence implies the existence of other regulatory elements in $c R h$ genes. It is speculated that those potential regulatory elements might locate within the well-conserved upstream regions between $c R h-I$ and $c R h-I I$ genes. According to transgenic studies of rhodopsin upstream regulatory regions, the proximal upstream portion $(\sim 300 \mathrm{bp})$ is prerequisite and sufficient for photoreceptor-specific expression of the reporter gene. Meanwhile, sequences of more distal regions are responsible for accurate expression patterns and higher expression levels (Batni et al., 1996; Knox et al., 1998; Nie et al., 1996; Zack et al., 1991). Hence, it was postulated that the most proximally conserved region of $c R h$ upstream sequence may play a prominent role in controlling the photoreceptor-specific expression of fish rhodopsin. And, the other two more distally conserved regions may regulate the spatial or temporal expression patterns or function as an enhancer.

\subsection{Downstream flanking sequences analysis}

The downstream untranscribed regions of $c R h$ $I$ and $c R h-I I$ genes were sequenced from nt 1555 to 1915 and from nt 1653 to 1885 , respectively. Sequence alignment of the downstream region and a portion of cDNA sequences between the two types of $c R h$ gene revealed a highly conserved region with a $86.1 \%$ polynucleotide identity, which is located at nt 1466-1753 of $c R h-I$ gene or nt 1476-1763 of $c R h-I I$ gene. Three of the four polyadenylation signals of $c R h-I I \mathrm{cDNA}$ and one of the $c R h-I$ cDNA were also indicated (Fig. 1B). Interestingly, corresponding sequences of the two excess polyadenylation signals of $c R h$ $I I$ cDNA were found in the downstream flanking region of $c R h-I$ genomic DNA. In addition, the excess 88 bp of $c R h-I I$ cDNA shared $83 \%$ identity with a corresponding region of $c R h-I$ gene. This finding suggests that the polyadenylation signals may be alternatively chosen while transcribing rhodopsin mRNA.

\subsection{Type discrimination of $c R h$ in genome}

Two types of $c R h$ gene were differentiated us- ing Tfi I to restrict $\mathrm{PCR}$ products generated by type-specific primers (Fig. 3A). Type I specific primers generated a $c R h-I$ PCR product of 272 bp. Notably, this fragment was not cut by $T f i$ I. However, a $c R h-I I$ PCR product of 281 bp generated by type II specific primers was cleaved by $T f i$ into two fragments of 168 and $113 \mathrm{bp}$ (Fig. $3 \mathrm{~B}, \mathrm{C}$ ). Ninety carps from the local pond (TzuPei) were examined for the distribution of two types of $c R h$ gene. The results showed that only two fish $(2.2 \%$ of total samples) exhibited merely $c R h-I$ genotype, and 19 fish (21.1\%) exhibited merely $c R h-I I$ genotype. However, most of them $(76.7 \%)$ carried both $c R h-I$ and $c R h-I I$ genotypes. Similar results were also observed with carps from a geographically different pond (LuKang). Furthermore, the distribution of two types of $c R h$ gene was irrelevant to the sex or size of fish. And there seemed to be no noticeable differences in terms of morphological appearance between carps showing only one $c R h$ type and the ones showing both. Since not every carp carries both $c R h-I$ and $c R h-I I$ genes, the two types of $c R h$ gene are less likely to be two distinct genes but two rhodopsin alleles in the carp population.

The common carp is a phylogenetically tetraploid fish. In addition to the fact that there is only one rhodopsin gene in diploid vertebrates, the existence of two types of $c R h$ gene may be attributed to tetraploidy, which is a similar event of the two myc genes of carp (Zhang et al., 1995). Subsequent to the original tetraploidization event, one of the two duplicate genes could have been silenced in their expression (Ferris and Whitt, 1977). In this study, RT-PCR was performed using retinal total RNA to determine whether or not one of the duplicated genes encoding rhodopsin has been silenced in a carp carrying both $c R h-I$ and $c R h-I I$ genes. These results demonstrated that both $c R h-I$ and $c R h-I I$ mRNAs were expressed at an approximately equal level in both eyes (Fig. 4). Related investigations have indicated that the tetraploid $X$. laevis has two types of rhodopsin corresponding to two morphologically distinct rod cells (Rohlich et al., 1989; Batni et al., 1996). In contrast, the rod cells of carp carrying both types of $c R h$ gene were not morphologically differentiated into two types under light microscopic observation (data not shown). 
A

\begin{tabular}{|c|c|}
\hline RHOl-f & 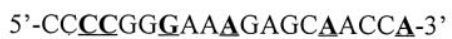 \\
\hline & 5'-CCAGGGAAACGAGCGACCG-3' \\
\hline
\end{tabular}

RHO1-r

5'-CATGCCTCTACAATCACAACAAA-3'

RHO2-r .5'-CATGCCTCTAAAATCACAACAAC-3'

cRh-I

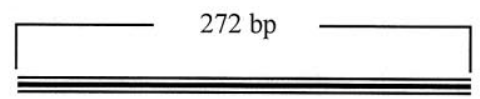

1244

$1515(\mathrm{bp})$

cRh-II

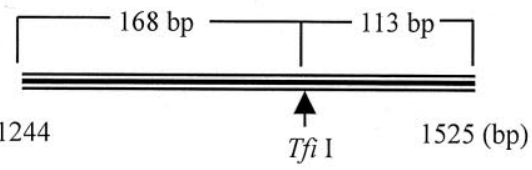

C

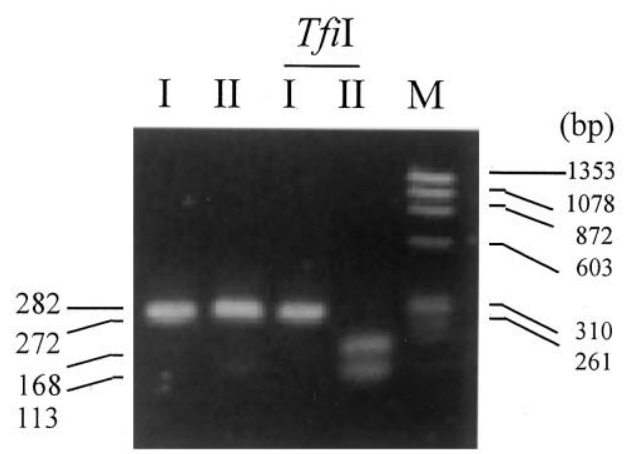

Fig. 3. Determination of two types of $c R h$ gene via polymerase chain reaction (PCR) and restriction analysis. (A) Sequences of type-specific primers. Specific primers for $c R h-I$ gene: forward RHO1-f and reverse RHO1-r; for $c R h-I I$ gene: forward RHO2-f and reverse RHO2-r. The different nucleotides between the two types of primers were underlined and in boldface. (B) Schematic of the expected molecular sizes of PCR products generated by type-specific primers. (C) Agarose gel electrophoresis of PCR products of $c R h-I$ (I) and $c R h-I I$ (II) genes, and their $T f$ I I restriction patterns. Lane M: molecular weight marker, Hae III-digested $\phi$ X174.

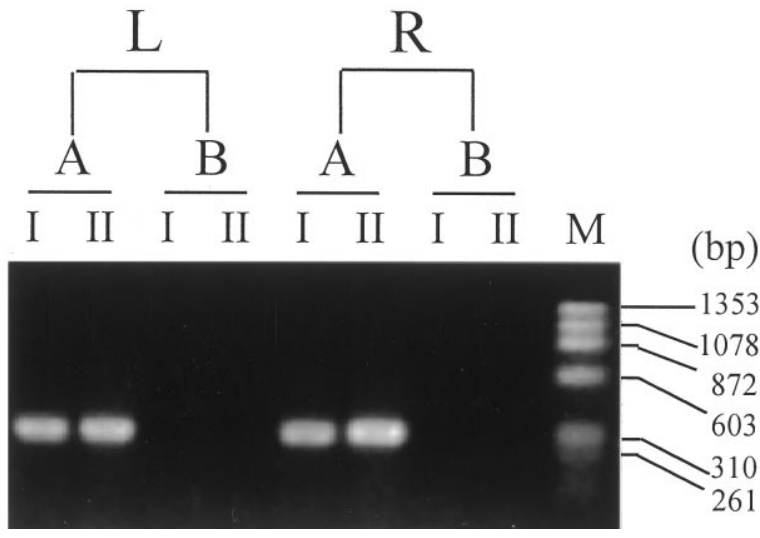

Fig. 4. Transcriptional patterns of $c R h-I$ and $c R h-I I$ genes of a carp carrying both types $c R h$ gene. Retinal RNAs extracted from left (L) and right (R) eyes of a carp were subjected to RT-PCR in the presence (A) and absence (B) of reverse transcriptase using $c R h-I$ (I) and $c R h-I I$ (II) specific primers. Lane M: molecular weight marker, HaeIII-digested $\phi$ X174.

\section{Conclusions}

(1.) Molecular structures of two types of carp rhodopsin gene, namely $c R h-I$ and $c R h-I I$, have been determined. Comparison of the upstream flanking sequences of the two types of $c R h$ gene reveals three highly conserved regions, which are at $\mathrm{nt}-1262$ to $-614,-539$ to -419 and -166 to +97 , with $78.0,79.3$ and $92.3 \%$ identities, respectively.

(2.) The sequence of the proximal upstream flanking region of $c R h$ genes shows homologies to consensus recognition sites for transcription factors, $\mathrm{Crx}$ and $\mathrm{Nrl}$, which are involved in photoreceptor-specific expression.

(3.) Two types of $c R h$ gene are clearly discriminated from each carp via PCR and restriction analysis. Most carps carry both types of $c R h$ gene, however, there are still carps possessing either $c R h-I$ or $c R h-I I$ genotype.

(4.) In a carp carrying both types of $c R h$ gene, none of the genes is silenced but are expressed equally in both eyes.

\section{Acknowledgements}

The authors wish to thank Mr Kuo-Ching Ma for assisting in multiple sequence alignments, and $\mathrm{Mr}$ Hung-Kuang Peng, director of Tzu-Pei branch, Taiwan Fisheries Research Institute (TFRI), and Mr Jong-Yih Lai, director of Lu- 
Kang branch, TFRI, for providing fish. This work was supported by the National Science Council, R.O.C., under NSC 87-2611-B-002-003.

\section{References}

Archer, S.N., Hirano, J., 1998. Rod opsin sequence in the John Dory: further evidence for the spectral tuning of rhodopsin. J. Fish Biol. 52, 209-212.

Baehr, W., Falk, J.D., Bugra, K., Triantaafyllos, J.T., McGinnis, J.F., 1988. Isolation and analysis of the mouse opsin gene. FEBS Lett. 238, 253-256.

Batni, S., Scalzetti, L., Moody, S., Knox, B.E., 1996. Characterization of the Xenopus rhodopsin gene. J. Biol. Chem. 271, 3179-3186.

Bennett, J., Sun, D., Kariko, K., 1995. Sequence analysis of the 5.34-kb $5^{\prime}$ flanking region of the human rhodopsin-encoding gene. Gene 167, 317-320.

Chen, S., Zack, D.J., 1996. Ret 4, a positive acting rhodopsin regulatory element identified using a bovine retina in vitro transcription system. J. Biol. Chem. 271, 28549-28557.

Chen, N., Ma, J.X., Corson, D.W., Hazard, E.S., Grouch, R.K., 1996. Molecular cloning of a rhodopsin gene from salamander rods. Invest. Ophthalmol. Visual Sci. 37, 1907-1913.

Chen, S., Wang, Q.L., Nie, Z., Sun, H., Lennon, G., Copeland, N.G., Gilbert, D.J., Jenkins, N.A., Zack, D., 1997. Crx, a novel otx-like paired-homeodomain protein, binds to and transactivates photoreceptor cell-specific genes. Neuron 19, 1017-1030.

Ferris, S.D., Whitt, G.S., 1977. The evolution of duplicate gene expression in the carp (Cyprinus carpio). Experientia 33, 1299-1301.

Fitzgibbon, J., Hope, A., Slobodyanyuk, S.J., Bellinggham, J., Bowmaker, J.K., Hunt, D.M., 1995. The rhodopsin-encoding gene of bony fish lacks introns. Gene 64, 273-277.

Hall, M.D., Hoon, M.A., Ryba, N.J.P., Pottinger, J.D.D., Keen, J.N., Saibil, H.R., Findlay, J.B.C., 1991. Molecular cloning and primary structure of squid (Loligo forbesi) rhodopsin, a phospholipase C-directed G-protein-linked receptor. Biochem. J. (Lond) 274, 35-40.

Hara-Nishimura, I., Kondo, M., Nishimura, M., Hara, R., Hara, T., 1993. Cloning and nucleotide sequence of cDNA for rhodopsin of the squid Todarodes pacificus. FEBS Lett. 317, 5-11.

Hisatomi, O., Iwasa, T., Tokunaga, F., Yasui, A., 1991. Isolation and characterization of lamprey rhodopsin cDNA. Biochem. Biophys. Res. Commun. 174, $1125-1132$.

Johnson, R.L., Grant, K.B., Zankel, T.C., Boehm, M.F., Merbs, S.L., Nathans, J., Nakanishi, K., 1992. Cloning and expression of goldfish opsin sequences. Biochemistry 32, 208-214.
Kawamura, S., Yokayama, S., 1994. Cloning of the rhodopsin-encoding gene from the rod-less lizard Anolis carolinensis. Gene 149, 267-270.

Knox, B.E., Schlueter, C., Sanger, B.M., Green, C.B., Besharse, J.C., 1998. Transgene expression in Xenopus rods. FEBS Lett. 423, 117-121.

Kumar, R., Chen, S., Scheurer, D., Wang, Q.L., Duh, E., Sung, C.H., Rehemtulla, A., Swaroop, A., Adler, R., Zack, D.J., 1996. The bZIP transcription factor Nrl stimulates rhodopsin promoter activity in primary retinal cell cultures. J. Biol. Chem. 271, 29612-29618.

Lim, J., Chang, J.L., Tsai, H.J., 1997. A second type of rod opsin cDNA from the common carp (Cyprinus carpio). Biochim. Biophys. Acta. 1352, 8-12.

Morabito, M.A., Yu, X., Barnstable, C.J., 1991. Characterization of developmentally regulated and retina-specific nuclear protein binding to a site in the upstream region of the rat opsin gene. J. Biol. Chem. 266, 9667-9672.

Nathans, J., Hogness, D.S., 1983. Isolation, sequence analysis, and intron-exon arrangement of the gene encoding bovine rhodopsin. Cell 34, 807-814.

Nathans, J., Hogness, D.S., 1984. Isolation and nucleotide sequence of the gene encoding human rhodopsin. Proc. Natl. Acad. Sci. USA 81, 48514855.

Nickells, R.W., Burgoyne, C.F., Quigley, H.A., Zack, D.J., 1995. Cloning and characterization of rod opsin cDNA from the old world monkey, Macaca fascicularis. Invest. Ophthalmol. Visual Sci. 36, 72 82.

Nie, Z., Chen, S., Kumar, R., Zack, D.J., 1996. RER, an evolutionary conserved sequence upstream of the rhodopsin gene, has enhancer activity. J. Biol. Chem. 271, 2667-2675.

O'Brien, J., Ripps, H., Al-Ubaidi, M.R., 1997. Molecular cloning of a rod opsin cDNA from the skate retina. Gene 193, 141-150.

Petersen-Jones, S.M., Sohal, A.K., Sargan, D.R., 1994. Nucleotide sequence of the canine rod-opsin-encoding gene. Gene 143, 281-284.

Rehemtulla, A., Warwar, R., Kumar, R., Ji, X., Zack, D.J., Swaroop, A., 1996. The basic motif-leucine zipper transcription factor $\mathrm{Nrl}$ can positively regulate rhodopsin gene expression. Proc. Natl. Acad. Sci. USA 93, 191-195.

Rohlich, P., Szel, A., Papermaster, D.S., 1989. Immunocytochemical reactivity of Xenopus laevis retinal rods and cones with several monoclonal antibodies to visual pigments. J. Comp. Neurol. 290, $105-117$.

Rose, M.H., Reith, E.J., Romrell, L.J., 1989. Histology: A Text and Atlas, 2nd edition. Williams and Wilkins, Baltimore, MD. 
Saha, M.S., Grainger, R.M., 1993. Early opsin expression in Xenopus embryos precedes photoreceptor differentiation. Mol. Brain Res. 17, 307-318.

Sambrook, J., Fritsch, E.F., Maniatis, T., 1989. Molecular Cloning: A Laboratory Manual. Cold Spring Harbor Laboratory, Cold Spring Harbor, NY.

Takao, M., Yasui, A., Tokunaga, F., 1988. Isolation and sequence determination of the chicken rhodopsin gene. Vis. Res. 28, 471-480.

Tsai, H.J., Shih, S.R., Kuo, C.M., Li, L.K., 1994. Molecular cloning of the common carp (Cyprinus carpio) rhodopsin cDNA. Comp. Biochem. Physiol. 109B, 81-88.

Yu, X., Leconte, L., Martinez, J.A., Barnstable, C.J.,
1996. Shared nuclear protein binding sites in the upstream region of the rat rod opsin gene. J. Neurochem. 67, 2494-2504.

Zack, D.J., Bennett, J., Wang, Y., Davenport, C., Klaunberg, B., Gearhart, J., Nathans, J., 1991. Unusual topology of bovine rhodopsin promoter-lacZ fusion gene expression in transgenic mouse retinas. Neuron 6, 187-199.

Zhang, H., Yokoyama, S., 1997. Molecular evolution of the rhodopsin gene of marine lamprey, Petromyzon marinus. Gene 191, 1-6.

Zhang, H., Okamoto, N., Ikeda, Y., 1995. Two c-myc genes from a tetraploid fish, the common carp (Cyprinus carpio). Gene 153, 231-236. 